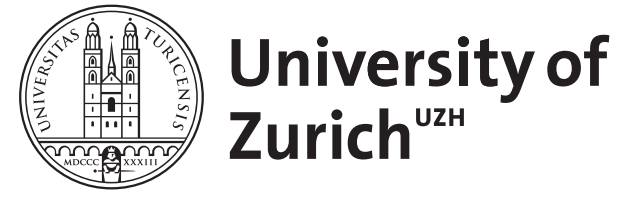

\title{
Indications of pediatric tonsillectomy
}

\author{
Gysin, C
}

\begin{abstract}
Possible indications for tonsillectomy include sleep apnea and other obstructive sleep-related breathing disorders, recurrent tonsillitis, peritonsillar abscess, periodic fever, aphthous stomatitis, pharyngitis, adenitis (PFAPA), and other miscellaneous rare conditions. Over the last century indications have changed, with a decrease in infectious causes and an increase in sleep apnea disorders. Sleep apnea in children is difficult to diagnose short of polysomnography (PSG) which is expensive and disturbing, especially in young children. In sleep apnea confirmed by PSG, tonsillectomy relieves the trouble in close to $80 \%$ of patients. What remains unclear is how to diagnose sleep-related breathing disorders without PSG and the efficacy of tonsillectomy in this population. Recurrent tonsillitis is generally poorly documented and randomized studies assessing the efficacy of tonsillectomy are sparse. When frequent infections are present for several years ( $>7$ episodes $/ 1$ year, $>5 / 2,>3 / 3$ ) some benefit from tonsillectomy could be found. If fewer infectious episodes are present, the benefit of tonsillectomy is low. Peritonsillar abscess tends to be treated with quinsy tonsillectomy. Some PFAPA and psoriasis children might benefit from tonsillectomy. Tonsillectomy for other conditions is not warranted.
\end{abstract}

DOI: https://doi.org/10.1159/000342329

Posted at the Zurich Open Repository and Archive, University of Zurich

ZORA URL: https://doi.org/10.5167/uzh-85499

Journal Article

Published Version

Originally published at:

Gysin, C (2013). Indications of pediatric tonsillectomy. ORL: Journal for Oto-Rhino-Laryngology and its Related Specialties, 75(3):193-202.

DOI: https://doi.org/10.1159/000342329 


\title{
Indications of Pediatric Tonsillectomy
}

\author{
Claudine Gysin \\ Division of Pediatric Otolaryngology, University Children's Hospital, Zurich, Switzerland
}

\section{Key Words}

Tonsillectomy $\cdot$ Indications $\cdot$ Pediatric · OSAS · Tonsillitis

\begin{abstract}
Possible indications for tonsillectomy include sleep apnea and other obstructive sleep-related breathing disorders, recurrent tonsillitis, peritonsillar abscess, periodic fever, aphthous stomatitis, pharyngitis, adenitis (PFAPA), and other miscellaneous rare conditions. Over the last century indications have changed, with a decrease in infectious causes and an increase in sleep apnea disorders. Sleep apnea in children is difficult to diagnose short of polysomnography (PSG) which is expensive and disturbing, especially in young children. In sleep apnea confirmed by PSG, tonsillectomy relieves the trouble in close to $80 \%$ of patients. What remains unclear is how to diagnose sleep-related breathing disorders without PSG and the efficacy of tonsillectomy in this population. Recurrent tonsillitis is generally poorly documented and randomized studies assessing the efficacy of tonsillectomy are sparse. When frequent infections are present for several years ( $>7$ episodes/ 1 year, $>5 / 2,>3 / 3$ ) some benefit from tonsillectomy could be found. If fewer infectious episodes are present, the benefit of tonsillectomy is low. Peritonsillar abscess tends to be treated with quinsy tonsillectomy. Some PFAPA and psoriasis children might benefit from tonsillectomy. Tonsillectomy for other conditions is not warranted.
\end{abstract}

Copyright (C) 2013 S. Karger AG, Basel

Tonsillectomy with or without adenoidectomy (TA) is one of the most often performed surgical procedures during childhood. At the beginning of the 20th century, recurrent tonsillitis was the main reason for removal of the tonsils, but tonsillectomy was also performed for several conditions not really related to tonsils. As a result, TA represented $30-50 \%$ of all pediatric surgeries in the 1930s [1]. Already at that time, publications began raising concerns about the indications and the benefits of tonsillectomy, as well as its potential effect on immunity. The advent of antibiotics in the 1950s resulted in a dramatic decrease in the overall 
number of tonsillectomies. In the USA, the frequency dropped from 1,400,000 TAs per year in 1959 to 500,000 in 1979 [1,2]. The same trend was observed in the UK, with a drop from 200,000 tonsillectomies per year in 1930 to 50,000 at the beginning of the 21st century [3]. Probably as a result of the end of 'mass tonsillectomies', the first cases of a cor pulmonale with pulmonary hypertension and congestive heart failure reversible after TA were reported in the 1960s, and this condition was subsequently named obstructive sleep apnea syndrome (OSAS). A shift of the indications for tonsillectomies ensued, and sleep-disordered breathing has now become the main reason for TA in western countries $[2,4]$.

Although tonsillectomy is a frequently performed procedure, there is a wide variability between countries and within countries [3,5] regarding tonsillectomy rates. Van den Akker et al. [6] evaluating the rates of pediatric TA in two age groups (0-14 and 15-19 years), found rates varying from 19 per 10,000 children in Canada to 118 per 10,000 in Northern Ireland in the younger group and from 19 per 10,000 in Canada to 76 per 10,000 in Finland in the adolescent group. A 5-year audit in England found a sevenfold variation in tonsillectomy rate across local authority areas [3]. Many reasons have been suggested to explain this large variability, including the availability of medical services, cultural differences, training of the health care providers, but the main explanation might be the lack of consensus regarding the indications for tonsillectomy.

The series published during the last 30 years show a clear shift in the indications of tonsillectomy. Sleep-disordered breathing is now the main reason for TA in children. All studies published in the last few years show this trend, which is even more obvious in children under 3 years of age, where OSAS reaches $90-100 \%$ of indications. In older children, infections are more frequent indications for TA $[1,2]$.

\section{Obstructive Sleep Apnea Syndrome}

Pediatric OSAS is part of an entity named obstructive sleep-disordered breathing. This entity includes a whole spectrum of obstructive conditions, going from primary or habitual snoring to upper airway resistance syndrome and to OSAS. Primary snoring is defined as snoring without associated apneas or hypopneas, hypoxemia, hypercapnia or sleep fragmentation [7]. Upper airway resistance syndrome was first described in 1982 by Guilleminault et al. [8] and is defined as an increased negative thoracic pressure during inspiration, leading to arousals and sleep fragmentation, but without apneas or hypopneas, or hypoxemia. OSAS is 'a disorder of breathing during sleep characterized by prolonged partial upper airway obstruction and/or intermittent complete obstruction/obstructive apnea that disrupts normal ventilation during sleep and normal sleep patterns'. Until recently, primary snoring was supposed to be a benign condition, but some studies suggest that snoring could also have neurobehavioral implications in children $[9,10]$.

The incidence of pediatric OSAS is difficult to establish precisely, but is estimated between 1 and $3 \%[7,11]$ of the pediatric population. Adenoid and tonsil hypertrophy is the most frequent etiology of pediatric OSAS. The peak incidence of pediatric OSAS is in preschool children, which is also the period when the tonsils and adenoids are mostly enlarged. Risk factors for pediatric OSAS are adenoid and tonsil hypertrophy, obesity, race (African American), male gender, neurological disorders, and craniofacial syndromes [7, $11]$.

OSAS is due to an upper airway collapse or resistance along the upper airway. Since adenotonsillar hypertrophy is the obvious clinical finding, it was initially held as the sole etiology of the airway obstruction and collapse. The lack of correlation between tonsil size and the severity of OSAS as well as the increased incidence of OSAS in neuromuscular disorders 
Gysin: Indications of Pediatric Tonsillectomy

Table 1. OSAS symptoms in children

\begin{tabular}{ll}
\hline Nocturnal symptoms & Diurnal symptoms \\
\hline Snoring & Nasal congestion \\
Mouth breathing & Mouth breathing \\
Apneas & Poor appetite \\
Labored breathing & Swallowing disorder \\
Subcostal retractions & Nausea, frequent vomiting \\
Hyperextended neck & Growth retardation \\
Restless sleep & Excessive daytime sleepiness \\
Arousals & Aggressive behavior \\
Sweating & Poor school performance \\
Enuresis & Attention deficit \\
\hline
\end{tabular}

point to neuromuscular abnormalities in the physiopathology of OSAS [12]. Like adults [13], children with OSAS [14] have a decreased response to airway collapse compared to healthy children, with lower ability to maintain airflow and to oppose/fight airway collapse $[13,14]$. Marcus et al. [14] documented a decrease in airway collapse in children after surgical treatment of OSAS, implying that the alteration of the airway collapse response is reversible and that an early treatment could be beneficial.

The complications associated with OSAS include pulmonary hypertension, cor pulmonale and congestive heart failure [15]. Since pediatricians are well aware of these pathologies, such complications have become rare. Failure to thrive is reported in $27-62 \%$ of OSAS cases [16], and is probably due in part to a reduction of insulin-like growth factor and of growth hormone secretion $[17,18]$. Other proposed mechanisms include a poor caloric intake associated with adenotonsillar hypertrophy, and an increased energy expenditure during sleep [19]. Failure to thrive is reversible after TA. Children with OSAS may also present neuropsychological complications, such as cognitive impairment, and therefore bad school performance $[20,21]$, excessive daytime sleepiness, and behavioral problems [22], such as hyperactivity. Children with hyperactivity have a higher prevalence of OSAS [23].

The gold standard to correctly diagnose an OSAS is polysomnography (PSG) [15]. However, correctly identifying children with OSAS short of PSG remains challenging. Although no really good prospective randomized large-scale studies have been performed about this public health problem, it seems that symptoms alone cannot distinguish between children with primary snoring and OSAS $[24,25]$. This should not prevent from recording a detailed medical history or to examine the patient.

The symptoms presented by children with OSAS are summarized in table 1 . Screening for snoring should be part of every medical visit in children, because OSAS is very unlikely in the absence of snoring. In case of a positive answer, a more detailed evaluation of the sleep quality is required. In 1997, Nieminen et al. [26] correlated PSG findings with medical history and found, as predictive factors for OSAS, apneas observed every night by the parents, constant snoring and restless sleep, mouth breathing during the day and at night, and previous adenoidectomy. Preutthipan et al. [25] reported similar findings, with some parameters showing a correlation with severe OSAS: observed cyanosis, obstructive apnea, extremely loud snoring, shaking the child for awakening, and being afraid of apnea while watching the child during sleep. However, these findings were again neither very sensitive nor specific.

Table 2 resumes the important points of the physical examination in OSAS children. It should include an endoscopy of the nose, an oral examination, as well as evaluation for micro- or retrognathia and midfacial hypoplasia. Evaluating the size of adenoids and tonsils is important, but there is unfortunately no good correlation between tonsil size and OSAS 
Gysin: Indications of Pediatric Tonsillectomy

Table 2. Physical signs found in OSAS children

\author{
General condition, weight, height, dark eyes \\ Mouth breathing, noisy breathing \\ Nose: nasal septal deviation, nasal congestion \\ Nasopharynx: adenoid hypertrophy \\ Mouth and oropharynx: tonsil hypertrophy, macroglossia, \\ high-arched palate, crossbite, overbite \\ Face: micrognathia, retrognathia, midfacial hypoplasia
}

[27], and normal examination does not exclude an OSAS. Children with craniofacial malformations merit endoscopic evaluation assessing the level of obstruction under general anesthesia.

Many questionnaires have been proposed in an attempt to help improving the accuracy of OSAS diagnosis. To date, there is no validated questionnaire to help differentiate between children with primary snoring or OSAS. Some newer questionnaires show better predictive values, but their use remains for research [28, 29].

Parents often bring an audio or video recording to illustrate their complaints. Audio recording does not allow distinguishing primary snoring from OSAS, but video recording seems to be more promising with a reported sensitivity of $94 \%$ and specificity of $68 \%$ [30].

Pulse oximetry recording at home is not a valuable tool for sleep-disordered breathing, as children may snore and have microarousals without hypoxemia. An abnormal pulse oximetry indicates an OSAS, but a normal pulse oximetry does not exclude an OSAS [31].

PSG has been recommended for every child who is potentially suffering from OSAS, but access to a sleep laboratory for every snoring child is not possible in numerous countries, without ignoring the fact that PSG is expensive, and in many cases will not change the management of the patient, i.e. removing adenoids and tonsils. Another problem is the lack of consensus on abnormal findings in a PSG and of competent specialists to evaluate the results. In 1992, Marcus et al. [32] published a landmark paper about normal polysomnographic values for children and adolescents, establishing that normally children rarely have apneas during sleep. Since then, other studies have reported similar findings, and an apnea/ hypopnea index (AHI) above 1 in children is considered to be abnormal. What has remained uncertain is the clinical significance of a slightly elevated AHI. Regarding the particularities of sleep in children, other parameters have to be taken into account beside the AHI, such as airflow obstruction, hypercapnia and arousals. Furthermore, the lack of consensus regarding clinically relevant values for children, the different equipment and different criteria used in different sleep laboratories make the sleep results difficult to evaluate and to compare. As a result, there has been some controversy in the last few years about PSG and its usefulness for all children with suspicion of sleep-disordered breathing. In an effort to provide some consensus for otolaryngologists regarding indications of PSG for children between 2 and 18 years, clinical practice guidelines have been published in 2011 [33]. It recommends performing a PSG before TA for children with comorbidities, such as obesity, Down syndrome, craniofacial abnormalities, and neuromuscular disorders. A PSG should also be done if the need for surgery is uncertain of when there is discordance between tonsillar size and the reported severity of sleep-disordered breathing.

Brietzke et al. [34] published a meta-analysis to evaluate the accuracy of medical history and clinical examination compared to PSG and found a poor correlation in 11 of 12 studies when PSG was used as the gold standard for diagnosis. The main problem is that 6 studies used either adult criteria for PSG or did not specify the criteria used for PSG. The conclusion of this meta-analysis is that medical history and clinical examination overdiagnose OSAS, 
Gysin: Indications of Pediatric Tonsillectomy

although this may be incorrect since the PSG criteria for pediatric OSAS were too restrictive (high adult AHI).

In another meta-analysis, Brietzke and Gallagher [35] evaluated the impact of TA on OSAS children evaluated with PSG pre- and postoperatively. They reported a success rate of TA as measured by PSG of $82 \%$ (52-100\%).

Ambulatory polygraphy has been proposed to allow sleep evaluation at home. An ambulant polygraphy should include the same measures as PSG except electroencephalography. A few adult studies comparing the results between PSG and polygraphy on the same patients concluded that polygraphy might be a valid alternative to PSG. The advantages of polygraphy include a study of the sleep in a home setting with fewer disturbances and a lower cost. Unfortunately, the literature regarding children is very scarce on this topic. In our experience, ambulatory polygraphy is a useful tool in children older than 6 years. For younger children, the measurements at home are not reliable and should be avoided.

In summary, the evaluation of snoring and OSAS in children still remains an art without a firm evidence-based decision tree. Medical history and clinical examination continues to be the most important tool for most pediatric patients with OSAS due to adenotonsillar hypertrophy. There is no consensus about normal pediatric PSG values, which may contribute to the poor correlation between medical history and clinical examination. PSG is not feasible in all cases, and should be reserved for patients with other comorbidities or when there is a discrepancy between medical history and clinical examination. Polygraphy might be a useful tool, but is not advocated for children less than 6 years of age. No other simple and accurate diagnostic test is available. Therefore the decision to perform TA in healthy children is still based on history and physical examination. In properly selected children with OSAS, TA cures the problem in most of them.

\section{Recurrent Tonsillitis}

Recurrent tonsillitis is a bacterial infection of the oropharynx due to group $A \beta$-hemolytic streptococci (GABHS), and is responsible for approximately $15 \%$ of sore throat episodes in children [36], the remaining being viral pharyngitis. Involvement of other bacteria is quite uncommon. Bacterial tonsillitis is very uncommon under 2 years of age, probably because of a decreased attachment of GABHS to pharyngeal cells. Tonsillitis is typically a self-limited localized inflammation of the oropharynx lasting 3-5 days. In most cases, symptoms resolve spontaneously. An antibiotic therapy reduces the duration of symptoms, and the incidence of localized spread and suppurative complications. The main reason for treatment is to avoid rheumatic fever, which can be prevented by antibiotics given up to 9 days after the beginning of symptoms.

The main issue is that GABHS tonsillitis cannot be correctly diagnosed clinically. A very useful criterion is the modified Centor score [37]; it allows 1 point for the following criteria: absence of cough, swollen and tender cervical lymph nodes, fever above $38^{\circ} \mathrm{C}$, tonsil with exudates, and patient younger than 14 years. When the score is $0-1$, there is no need for further evaluation or treatment, because the probability of GABHS tonsillitis is under $5 \%$. If the score is 4 or above, one should consider antibiotic treatment without further tests because the probability of GABHS is above $50 \%$. For scores $2-3$, a swab test should be done before treating with antibiotics. In case of GABHS infection the symptoms should resolve very quickly under antibiotics. Unfortunately, GABHS tonsillitis is overdiagnosed, and in many cases patients receive an unnecessary antibiotic treatment for a viral infection [38]. Since GABHS tonsillitis is not correctly diagnosed, it is extremely difficult to perform trials for the role of tonsillectomy in treating this disease. 
In an attempt to evaluate the efficacy of tonsillectomy with or without adenoidectomy, Burton and Glasziou [39] performed a Cochrane review. Randomized trials comparing surgical treatment versus medical treatment published since 1966 were selected. They found 1 adult study with 70 patients [40] and 4 pediatric studies totalizing 719 children [41-43]. The studies were so heterogeneous that a meta-analysis could not be performed. The principal outcomes measured were the reduction in the number and severity of tonsillitis or sore throat, the reduction of the number of days with a sore throat, and the morbidity and mortality of surgery.

In 1984, Paradise et al. [41] reported on two parallel clinical trials in the same study. The first trial reported on 91 patients (out of 2,043 patients eligible for this TA study!!!) aged 3-15 years who were randomized to either TA or nonsurgery for recurrent throat infections. In the second trial, patients were assigned according to parental preference, and therefore this part is of low evidence. The inclusion criteria were quite strict: 7 episodes in 1 year or more than 5 per year for 2 years or 3 per year during 3 years. These episodes had to be clinically (fever, lymph nodes, tonsil exudates) documented, a swab had to be done in all cases, and the patient treated with antibiotics. After tonsillectomy, there was a statistically significant reduction of the number and severity of infectious episodes for the first 2 years, although nonoperated children had also a reduction of infections over time.

In the second Paradise trial [42] of 2002, the efficacy of tonsillectomy for 'moderately affected children' with recurrent throat infections was assessed. In a 3-arm trial, patients were randomized in a tonsillectomy group, a TA group and a nonsurgical control group. The inclusion criteria were less strict than in the previous trial, most patients had fewer (1-2 less) episodes of throat infections per year. The incidence of throat infection was significantly lower in the surgical group for each year of the 3-year follow-up period, but the benefit was very modest. There was no difference between tonsillectomy and TA. The authors concluded that, regarding the modest benefit of surgery, the complications after surgery (8\%), and the cost, there is no clear benefit of tonsillectomy for 'moderately affected children'.

In an open randomized controlled trial, van Staaij et al. [43] included 300 children aged 2-8 years requiring TA. The study was conducted in 21 centers. The ENT physician answered a questionnaire, including the indication for surgery prior to randomization to either TA or watchful waiting. The results did not show statistically significant differences between both groups in terms of fever episodes per year or in health-related quality of life. The authors conclude that watchful waiting is a good option for children with mild symptoms of throat infection.

In their review, Burton and Glasziou [39] concluded that patients should be made aware that uncertainties persist regarding the etiology of their sore throat and about the outcome after surgery. Patients have to be informed of the risks and complications of tonsillectomy. Those are rare, but may be significant in case of hemorrhage. Finally, 'it may have to be accepted that some patients will undergo "unnecessary surgery" in order for others to benefit, and that even well-informed and appropriately counseled patients are prepared to accept the risks and uncertainty of surgery'.

Many studies have reported a benefit from removing tonsils in children with recurrent tonsillitis in uncontrolled and nonrandomized studies. Many ENT clinics use the recommendations for tonsillectomy in children with recurrent throat infections as first described by Paradise et al. and recommended by the American Academy of ORL-HNS [44]. It remains very important for the clinician to better diagnose GABHS sore throat in children and document all episodes. Watchful waiting for tonsillectomy in case of mild recurrent tonsillitis is the best treatment option, especially in young children. When tonsillectomy is indicated, parents have to be well informed that sore throats are still possible after tonsillectomy. 
Gysin: Indications of Pediatric Tonsillectomy

\section{PFAPA Syndrome}

In 1987, Marshall et al. [45] described a new periodic fever syndrome of unknown etiology, which was called PFAPA (periodic fever/adenitis/pharyngitis/aphthous ulcer) syndrome. Patients had recurrent fever episodes occurring every 2-12 weeks for 5 days' duration, with fever being high $\left(40-41^{\circ} \mathrm{C}\right) .75 \%$ had also pharyngitis with an aphthous stomatitis, and two thirds had enlarged cervical lymph nodes. Onset of symptoms was always before the age of 5 years. Between episodes, patients were asymptomatic with a normal development. Antibiotic therapy or anti-inflammatory medication did not bring any improvement. Fever disappeared after administration of 1 or 2 doses of oral steroids (prednisone $1 \mathrm{mg} / \mathrm{kg}$ ), but did not prevent new fever episodes.

In 1999, 2 other studies reported the same features in 94 and 28 patients, respectively $[46,47]$. Diagnostic criteria are regularly recurring fever episodes with an early age of onset ( $<5$ years of age), symptoms in the absence of upper respiratory tract infection with at least one of the following clinical signs: aphthous stomatitis, cervical lymphadenitis, pharyngitis. Patients have to be completely asymptomatic between episodes with a normal growth, and cyclic neutropenia has to be excluded.

Oral doses of cortisone (usually once or twice $1 \mathrm{mg} / \mathrm{kg}$ prednisone) suppress fever, but not the next episode. In some cases, it has been reported that disease-free intervals could be shortened with steroid administration. In 2000, the first cases of symptom eradication were reported after tonsillectomy. Since that, many studies have shown the same results. Peridis et al. [48] published a meta-analysis in 2010 showing that the most effective nonsurgical treatment is corticosteroids, but this treatment does not prevent future episodes. Tonsillectomy was the most effective treatment with complete resolution of PFAPA syndrome in $64 \%$ of cases. Adenoidectomy does not play a role in this illness. The etiology is still unknown, but the efficacy of steroids and tonsillectomy suggest a possible inflammatory or immune etiology. Although PFAPA syndrome is a self-limited disorder, the disease course can be protracted and tonsillectomy should be regarded as the most efficient treatment option.

\section{Peritonsillar Abscess}

Peritonsillar abscess, a collection of pus between the tonsil and the superior constrictor muscle, is a relatively rare pathology in children. Treatment is either aspiration with a needle, incision or quinsy tonsillectomy. In children and adolescents, the treatment is almost always done under general anesthesia. There is no consensus in the literature regarding the best therapeutic modality in adults, and nothing addressing this issue specifically for the pediatric patient. Nevertheless, it has been shown that the risk of recurrence of peritonsillar abscess is higher in patients under 30 years, so it seems reasonable to perform a quinsy tonsillectomy in such cases. Our experience in children younger than 10 years is a lack of resolution of symptoms with conservative treatments, so in general we favor quinsy tonsillectomy.

\section{Miscellaneous (Tonsil Asymmetry, IgA Nephropathy, Psoriasis, Orthodontics)}

Tonsil asymmetry in children is often a reason for referral. Harley [49] reported $18 \%$ of asymmetric tonsils in a series of 258 children referred for tonsillectomies. Once removed, the volume of the tonsil specimen was similar on both sides. The asymmetry was due to statistically significant differences in the depth of tonsil fossa. Van Lierop et al. [50] reported similar findings in 2007 with no differences between clinically asymmetric tonsils. Diagnostic tonsil- 
Gysin: Indications of Pediatric Tonsillectomy

lectomy is indicated in children with tonsil asymmetry in case of rapid enlargement, cervical lymphadenopathy, or other clinical symptoms. There is no indication for tonsillectomy in case of isolated tonsil asymmetry in children.

Another reason for referral is dental occlusion. Nasal breathing is essential for normal occlusion, and mouth breathers present a higher incidence of malocclusion. Mouth breathing is most often due to adenoid hypertrophy. While adenoid size and thus adenoidectomy or adenotonsillectomy have been associated with malocclusion and its treatment, there is a lack of evidence for tonsillectomy in this problematic. Therefore, tonsillectomy is not indicated for malocclusion.

Psoriasis is a chronic autoimmune (T-cell-mediated) skin disease with a fluctuating course. There is a strong genetic component, but environmental factors also play a role. A strong association has been observed for many years between psoriasis guttata, a variant of psoriasis, and streptococcal tonsillitis. In a prospective randomized study, Thorleifsdottir et al. [51] evaluated the impact of tonsillectomy in psoriasis guttata children patients during 2 years. Overall, $86 \%$ of the patients had an improvement or regression of their psoriasis [51]. Further studies need to be done to evaluate more precisely the indication for tonsillectomy in this condition.

A controversial indication for tonsillectomy is IgA nephropathy, an immune complexmediated glomerulonephritis, actually the primary glomerulonephritis in the world. The cause of IgA nephropathy is unknown. The relation between IgA nephropathy and tonsils remains uncertain. Nevertheless, patients frequently show a worsening of their urinary findings in association with an upper airway infection. As a result, tonsillectomy has been proposed in patients with IgA nephropathy [52]. The results are uncertain [53], as many patients treated with tonsillectomy also received corticosteroids and, therefore, the indication of tonsillectomy in these patients remains unclear.

\section{Conclusion}

The most frequent indication for tonsillectomy is oropharyngeal obstruction secondary to tonsillar hypertrophy. While sleep apnea is a clear indication for tonsillectomy, in most children with tonsillar hypertrophy, the indication for tonsillectomy remains clinical. Recurrent tonsillitis is generally poorly documented and tonsillectomy is only indicated in frequent episodes of tonsillitis. Other indications for tonsillectomy, to be discussed on an individual basis, include peritonsillar abscess, PFAPA syndrome and psoriasis. As serious complications of tonsillectomy might occur, it is important that the indication for tonsillectomy is accurate.

\section{References}

1 Rosenfeld RM, Green RP: Tonsillectomy and adenoidectomy: changing trends. Ann Otol Rhinol Laryngol 1990; 99:187-191.

2 Parker NP, Walner DL: Trends in the indications for pediatric tonsillectomy or adenotonsillectomy. Int J Pediatr Otorhinolaryngol 2011;75:282-285.

3 Suleman M, Clark MP, Goldacre M, Burton M: Exploring the variation in paediatric tonsillectomy rates between English regions: a 5-year NHS and independent sector data analysis. Clin Otolaryngol 2010;35:111-117.

4 Erickson BK, Larson DR, St Sauver JL, Meverden RA, Orvidas LJ: Changes in incidence and indications of tonsillectomy and adenotonsillectomy, 1970-2005. Otolaryngol Head Neck Surg 2009;140:894-901.

5 Fedeli U, Marchesan M, Avossa F, Zambon F, Andretta M, Baussano I, Spolaore P: Variability of adenoidectomy/ tonsillectomy rates among children of the Veneto region, Italy. BMC Health Serv Res 2009;9:25.

6 Van den Akker EH, Hoes AW, Burton MJ, Schilder AG: Large international differences in (adeno)tonsillectomy rates. Clin Otolaryngol Allied Sci 2004;29:161-164. 
Gysin: Indications of Pediatric Tonsillectomy

7 Pediatric Pulmonology Subcommittee on Obstructive Sleep Apnea Syndrome A: Clinical practice guideline: diagnosis and management of childhood obstructive sleep apnea syndrome. Pediatrics 2002;109:704-712.

8 Guilleminault C, Winkle R, Korobkin R, Simmons B: Children and nocturnal snoring: evaluation of the effects of sleep related respiratory resistive load and daytime functioning. Eur J Pediatr 1982;139:165-171.

9 Brockmann PE, Urschitz MS, Schlaud M, Poets CF: Primary snoring in school children: prevalence and neurocognitive impairments. Sleep Breath 2012;16:23-29.

10 O’Brien LM, Mervis CB, Holbrook CR, Bruner JL, Klaus CJ, Rutherford J, Raffield TJ, Gozal D: Neurobehavioral implications of habitual snoring in children. Pediatrics 2004;114:44-49.

11 Rosen CL, Larkin EK, Kirchner HL, Emancipator JL, Bivins SF, Surovec SA, Martin RJ, Redline S: Prevalence and risk factors for sleep-disordered breathing in 8- to 11-year-old children: association with race and prematurity. J Pediatr 2003;142:383-389.

12 Edstrom L, Larsson H, Larsson L: Neurogenic effects on the palatopharyngeal muscle in patients with obstructive sleep apnoea: a muscle biopsy study. J Neurol Neurosurg Psychiatry 1992;55:916-920.

13 Gold AR, Marcus CL, Dipalo F, Gold MS: Upper airway collapsibility during sleep in upper airway resistance syndrome. Chest 2002;121:1531-1540.

14 Marcus CL, McColley SA, Carroll JL, Loughlin GM, Smith PL, Schwartz AR: Upper airway collapsibility in children with obstructive sleep apnea syndrome. J Appl Physiol 1994;77:918-924.

15 Cardiorespiratory sleep studies in children. Establishment of normative data and polysomnographic predictors of morbidity. American Thoracic Society. Am J Respir Crit Care Med 1999;160:1381-1387.

16 Katz ES, D’Ambrosio CM: Pediatric obstructive sleep apnea syndrome. Clin Chest Med 2010;31:221-234.

17 Nieminen P, Lopponen T, Tolonen U, Lanning P, Knip M, Lopponen H: Growth and biochemical markers of growth in children with snoring and obstructive sleep apnea. Pediatrics 2002;109:e55.

18 Bonuck KA, Freeman K, Henderson J: Growth and growth biomarker changes after adenotonsillectomy: systematic review and meta-analysis. Arch Dis Child 2009;94:83-91.

19 Marcus CL, Carroll JL, Koerner CB, Hamer A, Lutz J, Loughlin GM: Determinants of growth in children with the obstructive sleep apnea syndrome. J Pediatr 1994;125:556-562.

20 Gozal D: Sleep-disordered breathing and school performance in children. Pediatrics 1998;102:616-620.

21 Stein MA, Mendelsohn J, Obermeyer WH, Amromin J, Benca R: Sleep and behavior problems in school-aged children. Pediatrics 2001;107:E60.

22 Ali NJ, Pitson DJ, Stradling JR: Snoring, sleep disturbance, and behaviour in 4-5 year olds. Arch Dis Child 1993; 68:360-366

23 O’Brien LM, Holbrook CR, Mervis CB, Klaus CJ, Bruner JL, Raffield TJ, Rutherford J, Mehl RC, Wang M, Tuell A, Hume BC, Gozal D: Sleep and neurobehavioral characteristics of 5- to 7-year-old children with parentally reported symptoms of attention-deficit/hyperactivity disorder. Pediatrics 2003;111:554-563.

24 Carroll JL, McColley SA, Marcus CL, Curtis S, Loughlin GM: Inability of clinical history to distinguish primary snoring from obstructive sleep apnea syndrome in children. Chest 1995;108:610-618.

25 Preutthipan A, Chantarojanasiri T, Suwanjutha S, Udomsubpayakul U: Can parents predict the severity of childhood obstructive sleep apnoea? Acta Paediatr 2000;89:708-712.

26 Nieminen P, Tolonen U, Lopponen H, Lopponen T, Luotonen J, Jokinen K: Snoring children: factors predicting sleep apnea. Acta Otolaryngol 1997;529:190-194.

27 Nolan J, Brietzke SE: Systematic review of pediatric tonsil size and polysomnogram-measured obstructive sleep apnea severity. Otolaryngol Head Neck Surg 2011;144:844-850.

28 Montgomery-Downs HE, O’Brien LM, Holbrook CR, Gozal D: Snoring and sleep-disordered breathing in young children: subjective and objective correlates. Sleep 2004;27:87-94.

29 Chervin RD, Weatherly RA, Garetz SL, Ruzicka DL, Giordani BJ, Hodges EK, Dillon JE, Guire KE: Pediatric sleep questionnaire: prediction of sleep apnea and outcomes. Arch Otolaryngol Head Neck Surg 2007;133:216-222.

30 Sivan Y, Kornecki A, Schonfeld T: Screening obstructive sleep apnoea syndrome by home videotape recording in children. Eur Respir J 1996;9:2127-2131.

31 Brouillette RT, Morielli A, Leimanis A, Waters KA, Luciano R, Ducharme FM: Nocturnal pulse oximetry as an abbreviated testing modality for pediatric obstructive sleep apnea. Pediatrics 2000;105:405-412.

32 Marcus CL, Omlin KJ, Basinki DJ, Bailey SL, Rachal AB, Von Pechmann WS, Keens TG, Ward SL: Normal polysomnographic values for children and adolescents. Am Rev Respir Dis 1992;146:1235-1239.

33 Roland PS, Rosenfeld RM, Brooks LJ, Friedman NR, Jones J, Kim TW, Kuhar S, Mitchell RB, Seidman MD, Sheldon SH, Jones S, Robertson P: Clinical practice guideline: polysomnography for sleep-disordered breathing prior to tonsillectomy in children. Otolaryngol Head Neck Surg 2011;145:S1-S15.

34 Brietzke SE, Katz ES, Roberson DW: Can history and physical examination reliably diagnose pediatric obstructive sleep apnea/hypopnea syndrome? A systematic review of the literature. Otolaryngol Head Neck Surg 2004;131:827-832.

35 Brietzke SE, Gallagher D: The effectiveness of tonsillectomy and adenoidectomy in the treatment of pediatric obstructive sleep apnea/hypopnea syndrome: a meta-analysis. Otolaryngol Head Neck Surg 2006;134:979_ 984.

36 Pichichero ME: Group A beta-hemolytic streptococcal infections. Pediatr Rev 1998;19:291-302.

37 Centor RM, Witherspoon JM, Dalton HP, Brody CE, Link K: The diagnosis of strep throat in adults in the emergency room. Med Decis Making 1981;1:239-246. 
Gysin: Indications of Pediatric Tonsillectomy

38 Linder JA, Bates DW, Lee GM, Finkelstein JA: Antibiotic treatment of children with sore throat. JAMA 2005;294: 2315-2322.

39 Burton MJ, Glasziou PP: Tonsillectomy or adeno-tonsillectomy versus non-surgical treatment for chronic/ recurrent acute tonsillitis. Cochrane Database Syst Rev 2009:CD001802.

40 Alho OP, Koivunen P, Penna T, Teppo H, Koskela M, Luotonen J: Tonsillectomy versus watchful waiting in recurrent streptococcal pharyngitis in adults: randomised controlled trial. BMJ (Clin Res) 2007;334:939.

41 Paradise JL, Bluestone CD, Bachman RZ, Colborn DK, Bernard BS, Taylor FH, Rogers KD, Schwarzbach RH, Stool SE, Friday GA, et al: Efficacy of tonsillectomy for recurrent throat infection in severely affected children. Results of parallel randomized and nonrandomized clinical trials. N Engl J Med 1984;310:674-683.

42 Paradise JL, Bluestone CD, Colborn DK, Bernard BS, Rockette HE, Kurs-Lasky M: Tonsillectomy and adenotonsillectomy for recurrent throat infection in moderately affected children. Pediatrics 2002;110:7-15.

43 Van Staaij BK, van den Akker EH, Rovers MM, Hordijk GJ, Hoes AW, Schilder AGM: Effectiveness of adenotonsillectomy in children with mild symptoms of throat infections or adenotonsillar hypertrophy: open, randomised controlled trial. BMJ (Clin Res) 2004;329:651-650.

44 Baugh RF, Archer SM, Mitchell RB, Rosenfeld RM, Amin R, Burns JJ, Darrow DH, Giordano T, Litman RS, Li KK, Mannix ME, Schwartz RH, Setzen G, Wald ER, Wall E, Sandberg G, Patel MM: Clinical practice guideline: tonsillectomy in children. Otolaryngol Head Neck Surg 2011;144:S1-S30.

45 Marshall GS, Edwards KM, Butler J, Lawton AR: Syndrome of periodic fever, pharyngitis, and aphthous stomatitis. J Pediatr 1987;110:43-46.

46 Thomas KT, Feder HM Jr, Lawton AR, Edwards KM: Periodic fever syndrome in children. J Pediatr 1999;135: 15-21.

47 Padeh S, Brezniak N, Zemer D, Pras E, Livneh A, Langevitz P, Migdal A, Pras M, Passwell JH: Periodic fever, aphthous stomatitis, pharyngitis, and adenopathy syndrome: clinical characteristics and outcome. J Pediatr 1999;135:98-101.

48 Peridis S, Pilgrim G, Koudoumnakis E, Athanasopoulos I, Houlakis M, Parpounas K: PFAPA syndrome in children: a meta-analysis on surgical versus medical treatment. Int J Pediatr Otorhinolaryngol 2010;74:12031208.

49 Harley EH: Asymmetric tonsil size in children. Arch Otolaryngol Head Neck Surg 2002;128:767-769.

50 Van Lierop AC, Prescott CA, Fagan JJ, Sinclair-Smith CC: Is diagnostic tonsillectomy indicated in all children with asymmetrically enlarged tonsils? S Afr Med J 2007;97:367-370.

51 Thorleifsdottir RH, Sigurdardottir SL, Sigurgeirsson B, Olafsson JH, Sigurdsson MI, Petersen H, Arnadottir S, Gudjonsson JE, Johnston A, Valdimarsson H: Improvement of psoriasis after tonsillectomy is associated with a decrease in the frequency of circulating $\mathrm{T}$ cells that recognize streptococcal determinants and homologous skin determinants. J Immunol 2012;188:5160-5165.

52 Kodama S, Suzuki M: Tonsillectomy as part of the treatment for IgA nephropathy: cooperation between nephrologists and otolaryngologists. Clin Exp Nephrol 2007;11:258-259.

53 Mariotti AJ, Agrawal R, Hotaling AJ: The role of tonsillectomy in pediatric IgA nephropathy. Arch Otolaryngol Head Neck Surg 2009;135:85-87. 